\title{
Adoption of the Wet Surface Treatment Technique for the Improvement of Device Performance of Enhancement-Mode AlGaN/GaN MOSHEMTs for Millimeter-Wave Applications
}

\author{
Chun Wang ${ }^{1}$, Yu-Chiao Chen ${ }^{2}$, Heng-Tung Hsu ${ }^{3}{ }^{(D)}$, Yi-Fan Tsao $\left.{ }^{3}{ }^{(}\right)$, Yueh-Chin Lin ${ }^{1}$, Chang-Fu Dee 4 \\ and Edward-Yi Chang 1,2,3,* \\ 1 Department of Material Science Engineering, National Yang Ming Chiao Tung University, 1001 Tah Hsueh \\ Road, Hsinchu 30010, Taiwan; wangben2920.mse05g@nctu.edu.tw (C.W.); nctulin@yahoo.com.tw (Y.-C.L.) \\ 2 Department of Electrical Engineering, National Yang Ming Chiao Tung University, 1001 Tah Hsueh Road, \\ Hsinchu 30010, Taiwan; bigjj600@gmail.com \\ 3 International College of Semiconductor Technology, National Yang Ming Chiao Tung University, 1001 Tah \\ Hsueh Road, Hsinchu 30010, Taiwan; hthsu@nctu.edu.tw (H.-T.H.); elle1352.05g@g2.nctu.edu.tw (Y.-F.T.) \\ 4 Institute of Microengineering and Nanoelectronics (IMEN) Level 4, Research Complex, University \\ Kebangsaan Malaysia, Bangi 43600, Malaysia; cfdee@ukm.edu.my \\ * Correspondence: edc@mail.nctu.edu.tw
}

check for updates

Citation: Wang, C.; Chen, Y.-C.; Hsu, H.-T.; Tsao, Y.-F.; Lin, Y.-C.; Dee, C.-F.; Chang, E.-Y. Adoption of the Wet Surface Treatment Technique for the Improvement of Device Performance of Enhancement-Mode AlGaN/GaN MOSHEMTs for Millimeter-Wave Applications. Materials 2021, 14, 6558. https://doi.org/10.3390/ma14216558

Academic Editor: Albena Paskaleva

Received: 2 October 2021

Accepted: 28 October 2021

Published: 1 November 2021

Publisher's Note: MDPI stays neutral with regard to jurisdictional claims in published maps and institutional affiliations.

Copyright: (c) 2021 by the authors. Licensee MDPI, Basel, Switzerland. This article is an open access article distributed under the terms and conditions of the Creative Commons Attribution (CC BY) license (https:/ / creativecommons.org/licenses/by/ $4.0 /)$.

\begin{abstract}
In this work, a low-power plasma oxidation surface treatment followed by $\mathrm{Al}_{2} \mathrm{O}_{3}$ gate dielectric deposition technique is adopted to improve device performance of the enhancement-mode (E-mode) AlGaN/GaN metal-oxide-semiconductor high-electron-mobility transistors (MOSHEMTs) intended for applications at millimeter-wave frequencies. The fabricated device exhibited a threshold voltage $\left(\mathrm{V}_{\mathrm{th}}\right)$ of $0.13 \mathrm{~V}$ and a maximum transconductance $\left(\mathrm{g}_{\mathrm{m}}\right)$ of $484(\mathrm{mS} / \mathrm{mm})$. At $38 \mathrm{GHz}$, an output power density of $3.22 \mathrm{~W} / \mathrm{mm}$ with a power-added efficiency (PAE) of $34.83 \%$ were achieved. Such superior performance was mainly attributed to the high-quality $\mathrm{Al}_{2} \mathrm{O}_{3}$ layer with a smooth surface which also suppressed the current collapse phenomenon.
\end{abstract}

Keywords: GaN; HEMT; E-mode; wet surface treatment; power performance; millimeter-wave applications

\section{Introduction}

The quest for a high-capacity 5G network for increased data transmission requires wide bandwidth and high signal-to-noise ratio (SNR) to maintain the quality of service (QoS) of the system. Since the spectrum below $20 \mathrm{GHz}$ has been crowded with commercial applications, allocation of bandwidth wide enough to accommodate the required channel capacity is almost impossible. As a result, operating at millimeter-wave frequencies has been the only solution for next-generation communication systems targeting at multi-gigabit data transmission with minimum latency. In comparison with Si- and GaAs-based transistors, GaN-based HEMTs exhibit superior performance at high frequencies in terms of power density and efficiency due to the characteristics of the wide bandgap, high electron mobility and large breakdown field of GaN material. Successful demonstrations of the depletion-mode (D-mode) devices have been reported in [1-3].

Other than the D-mode devices, the E-mode devices exhibit certain advantages in terms of practical operations at system level. Since the devices require only positive supply, the complexity of the biasing network can greatly be reduced. Moreover, elimination of the negative supply also helps the suppression of the system noise. In the past, several approaches were reported for the development of E-mode devices. Fluorine plasma treatment was applied to insert negative charges into the barrier layer, resulting in a positive shift with the threshold voltage as a depletion region was formed in the 2DEG channel. A maximum output power density of $3.6 \mathrm{~W} / \mathrm{mm}$ and peak PAE of $42 \%$ were measured 
at $18 \mathrm{GHz}$ from the E-mode AlGaN/GaN heterojunction FET (HFET) [4]. However, the current collapse is a big issue caused by the plasma implantation. The technique of applying a p-type GaN layer under the gate region can help avoiding the damage caused by plasma. Normally-off HEMTs with the formation of the p-n junction exhibited the cut-off frequency $\left(f_{T}\right)$ and maximum oscillation frequency $\left(f_{\max }\right)$ of 6.0 and $9.8 \mathrm{GHz}$ by adopting a gate-all-around structure in [5].

Gate recess is the major technology for the realization of the E-mode devices [6-8]. The barrier thickness under $8 \mathrm{~nm}$ with a proper gate-recessed process exhibited excellent RF characteristics in terms of the $f_{T}$ and $f_{\text {max }}$ in [8]. The major issue with a gate recess process is the unavoidable damage to the surface leading to possible performance degradations. Thus, techniques of surface treatment, damage-free gate recess, and dielectric passivation have been proposed to suppress the possible damage that causes the current collapse phenomenon [9-15]. There are various surface treatments and cleaning methods, such as UV/ozone [16], wet chemical [17], plasma [18], descum [19] and $\mathrm{O}_{2}$ treatment [20] which have been adopted for the improvement of the surface states. For instance, with the $\mathrm{SF}_{6}$ plasma treatment, the gate leakage and pulse I-V characteristics were improved effectively due to the reduction in the amount of carbon on the semiconductor surface [18]. Besides, an $\mathrm{Al}_{2} \mathrm{O}_{3}$ dielectric layer under the gate region was adopted to suppress the hydrogen-induced weak bonds for leakage current reduction in [11]. The fabricated Emode metal-insulator-semiconductor HEMTs (MISHEMTs) demonstrated an output power density of $5.76 \mathrm{~W} / \mathrm{mm}$ and a PAE of $57 \%$ at $4 \mathrm{GHz}$.

In this work, we fabricated an enhancement-mode AlGaN/GaN metal-oxide-semiconductor high-electron-mobility transistor (MOSHEMT) using the wet surface treatment technology followed by the deposition of a high-quality $\mathrm{Al}_{2} \mathrm{O}_{3}$ layer. Compared with hydrochloric acid cleaning, a better surface morphology was achieved after the adoption of the wet surface treatment. Moreover, the imperfect layer of the gate region surface which included the native oxide and the bombardment damage caused by the plasma etching process could be effectively removed. Improvement in the device performance was observed with such surface treatment due to the suppression of the current collapse phenomenon. The maximum output power density and peak PAE were measured to be $3.22 \mathrm{~W} / \mathrm{mm}$ and $34.83 \%$, respectively, at $38 \mathrm{GHz}$.

\section{Materials and Methods}

Figure 1 shows the cross section of the thin-barrier AlGaN/GaN MOSHEMT grown on 4-inch Sapphire substrate by metal-organic chemical vapor deposition. The T-gate with asymmetric head toward the drain side was adopted for the purpose of the breakdownvoltage enhancement. Figure 2 displays the top view SEM images of AlGaN/GaN MOSHEMTs at different magnifications. The epitaxial structure consists of a $100 \mathrm{~nm}$ AlN nucleation layer, a $350 \mathrm{~nm}$ iron-doped GaN buffer layer, a $1700 \mathrm{~nm}$ i-GaN layer, a $1 \mathrm{~nm}$ AlN spacer layer, and a $10 \mathrm{~nm} \mathrm{Al}_{0.26} \mathrm{Ga}_{0.74} \mathrm{~N}$ barrier layer. Room temperature Hall effect measurement exhibits a sheet carrier density of $9.7 \times 10^{12} \mathrm{~cm}^{-2}$, a sheet resistance of $324 \Omega / \square$, and an electron mobility of $1980 \mathrm{~cm}^{2} / \mathrm{V} \cdot \mathrm{s}$, respectively. Figure 3 shows EDX analysis of aluminum and gallium elements. It is observed that the aluminum was rich in the AlGaN barrier and gradually decreased when it reached the GaN buffer layer. The cross-section HRTEM image is also shown in Figure 4. 

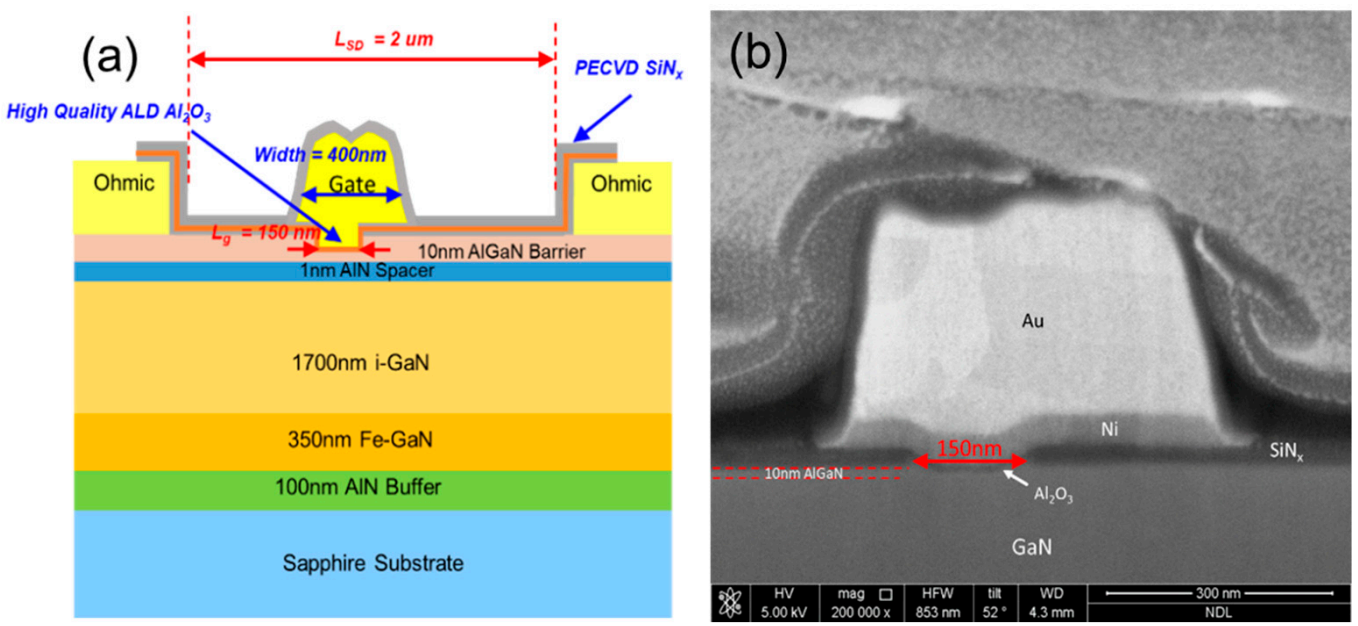

Figure 1. (a) Epitaxial structure and (b) scanning electron microscopy (SEM) image of the T-shape gate for the thin barrier AlGaN/GaN metal-oxide-semiconductor high-electron-mobility transistor (MOSHEMT).
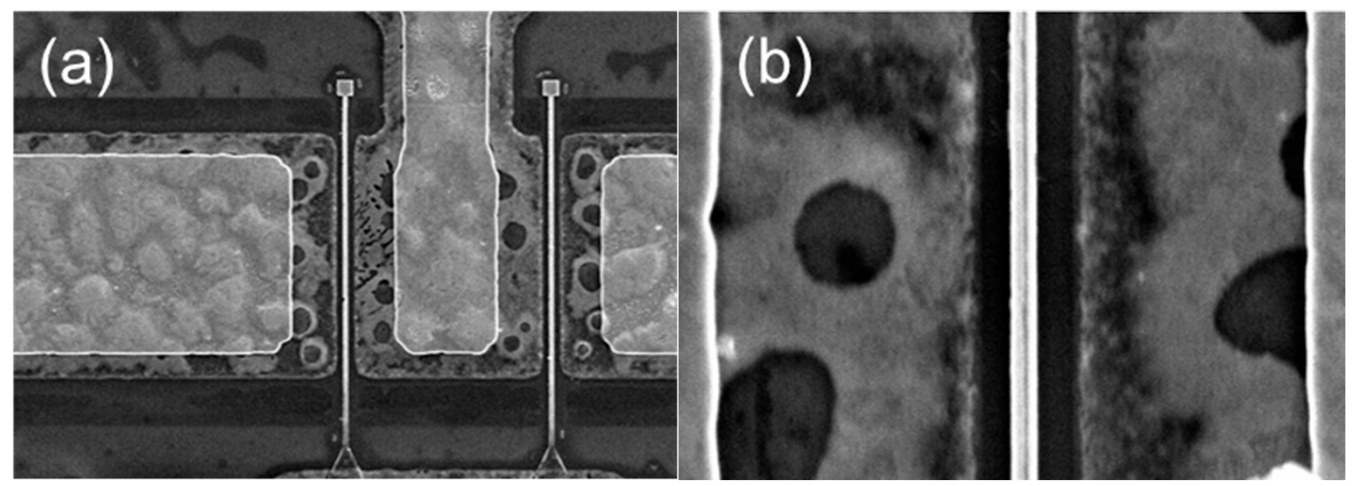

Figure 2. (a) Scanning electron microscope (SEM) image of top view of the high-electron-mobility transistor (HEMT) device and (b) SEM image of the magnification of the Source/Drain spacing region.
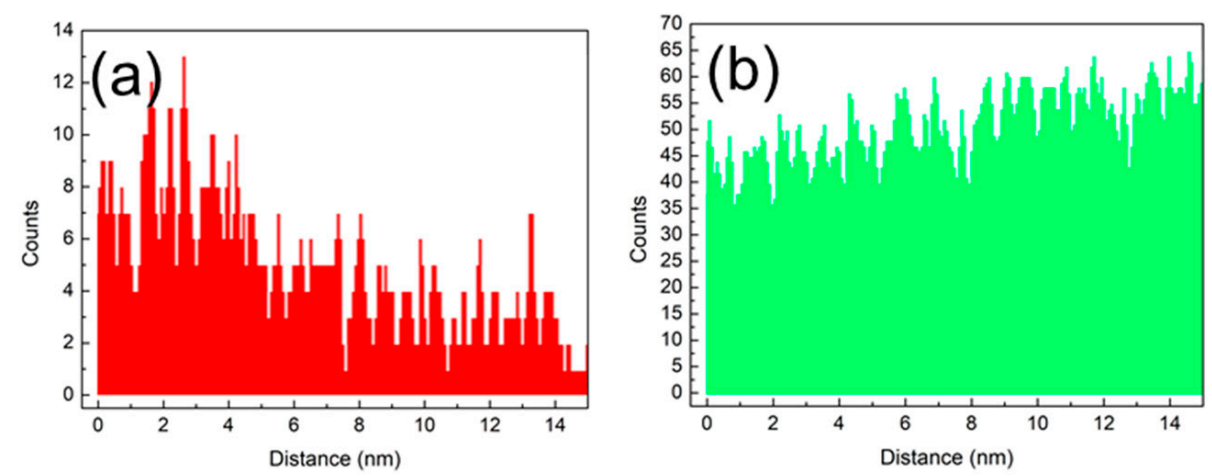

Figure 3. Energy-dispersive X-ray spectroscopy (EDX) analysis of (a) aluminum and (b) gallium element. 


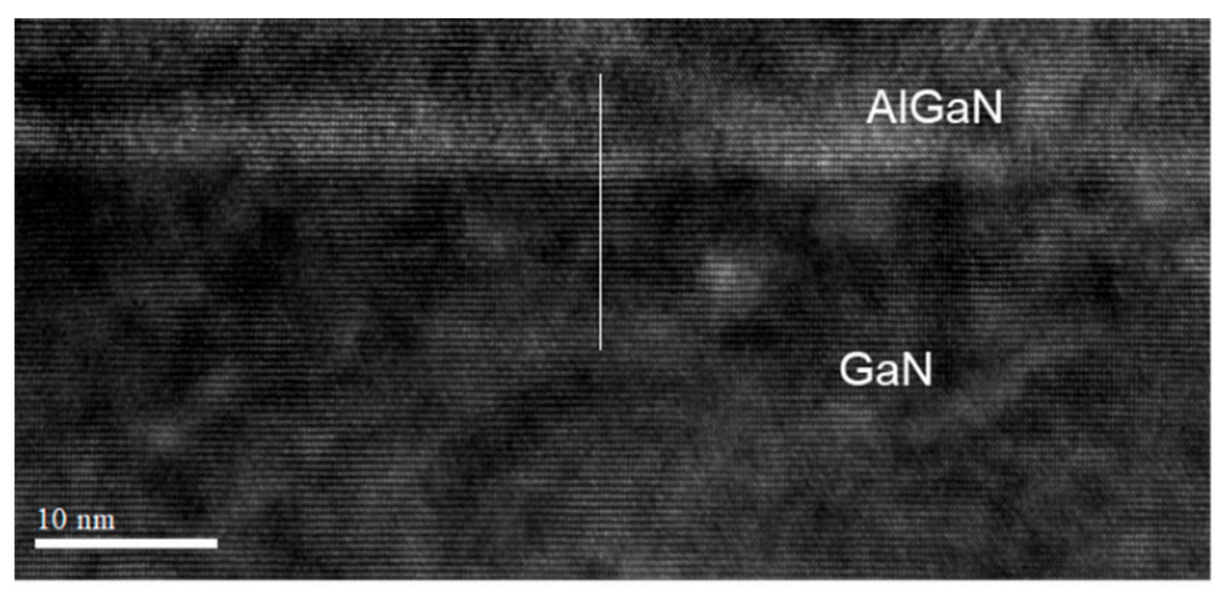

Figure 4. The cross-section high-resolution transmission electron microscopy (HRTEM) image of the interface.

Device fabrication started with the wafer cleaning by dipping in the acetone and isopropanol solution to remove the organic particles or contaminations. The ohmic contact consisted of a Ti/Al/Ni/Au metal stack deposited by ULVAC EVA650 E-gun evaporation system (EVA650, Ulvac, Hsinchu, Taiwan). Ohmic metal alloying was then formed at $820^{\circ} \mathrm{C}$ for $30 \mathrm{~s}$ in $\mathrm{N}_{2}$ ambient using a Premtek RTP-T41 rapid thermal annealing (RTA) system. A $25 \mathrm{~nm}-\mathrm{SiN}_{\mathrm{x}}$ was deposited by STS310PC plasma-enhanced chemical vapor deposition (PECVD) with in-situ nitrogen plasma treatment prior to the film deposition [21]. The $\mathrm{SiN}_{\mathrm{x}}$ film could reduce the dangling bond on the surface and act as hard mask at the recess region. The $150 \mathrm{~nm}$ gate foot was defined by using a $50 \mathrm{kV}$ JEOL e-beam lithography (EBL) system (JBX 6000 FS) and the gate region was opened by fluorine-based ICP dry etching to remove $\mathrm{SiN}_{\mathrm{x}}$ film. Next, the gate recess process was performed using $\mathrm{Cl}_{2}$-based plasma with the following parameters: $40 \mathrm{sccm}$ flow rate, 0.1 Pa pressure, and $200 \mathrm{~W}$ of RF power with $5 \mathrm{~W}$ of bottom bias. $\mathrm{O}_{2}$ plasma was performed by the ICP system (Nesca-20 plus, Cello Technology, Hsinchu, Taiwan) with low RF power of $50 \mathrm{~W}$ and the $5 \mathrm{~W}$ for the bottom bias. Afterwards, a thin oxide layer was formed on the surface. Then, the oxide layer was removed by wet surface treatment using $\mathrm{NH}_{4} \mathrm{OH}$ solution for 5 min. A $7 \mathrm{~nm} \mathrm{Al}_{2} \mathrm{O}_{3}$ insulator was deposited by a Fujitec G2 atomic layer deposition (ALD) system (Fujitec G2, Veeco, Plainview, NYC, USA) immediately after the surface treatment. The growth rate was $1 \AA$ /cycle for 70 cycles and the temperature was kept at $250{ }^{\circ} \mathrm{C}$. Afterwards, the active region was defined by nitrogen ion implantation. With the use of the ZEP/GL-2000 photoresists, the T-shape gate was formed as shown in Figure 1 and the width of the foot and head were $150 \mathrm{~nm}$ and $400 \mathrm{~nm}$. A $15 \mathrm{~nm} \mathrm{SiN}$ layer was deposited by PECVD after $\mathrm{Ni} / \mathrm{Au}$ gate metal deposition and the lift-off process. The recessed depth of the gate region was approximately $4 \mathrm{~nm}$. Finally, Ti/Au was deposited as an interconnect metal. The process flow is shown in Figure 5. The gate-source and gate-drain distance were $0.7 \mu \mathrm{m}$, and $1.1 \mu \mathrm{m}$, respectively.

Figure 6 shows the root mean square roughness of the AlGaN layer surface morphology by an atomic force microscope. Substantial reduction in the surface roughness from $0.66 \mathrm{~nm}$ to $0.4 \mathrm{~nm}$ was observed for the device with surface treatment. Moreover, an AFM image with an atomically clean morphology was achieved after applying the treatment. 


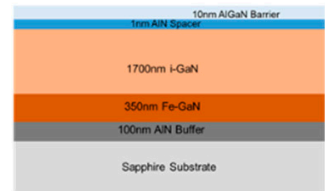

(a) Structure of Epitaxy Layers

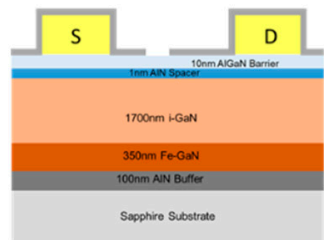

(d) Gate Foot Defined by E-beam Lithogra

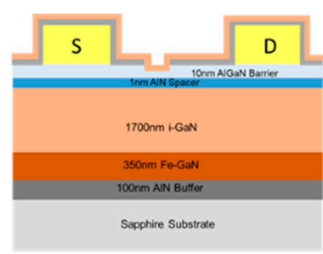

(g) $\mathrm{Al}_{2} \mathrm{O}_{3}$ insulator

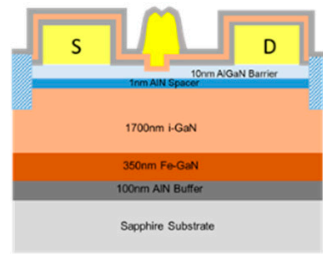

(j) $\mathrm{SiN}_{\mathrm{x}}$ Deposition

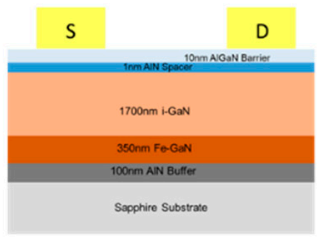

(b) Source/Drain Ohmic Contact Fabrication

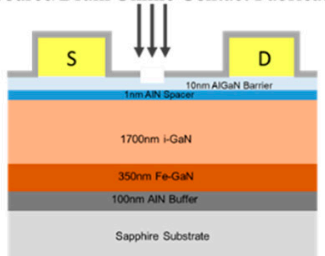

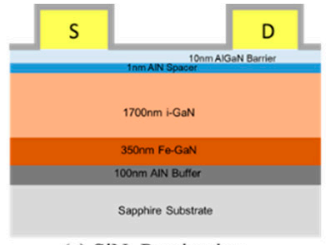

(c) $\mathrm{SiN}_{\mathrm{x}}$ Passivation

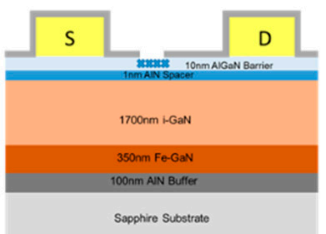

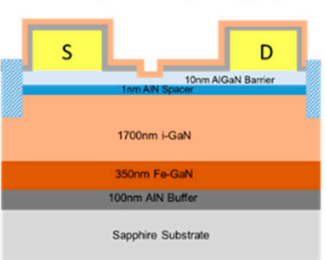

(h) Nitrogen Ion Implantation

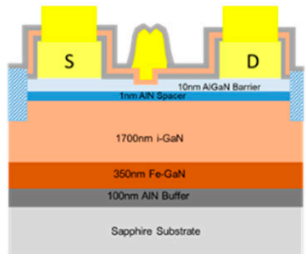

(k) Via Opening and Pad Fabrication

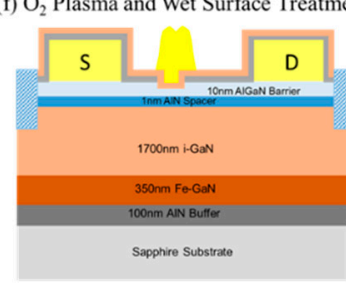

(i) Gate Formation

Figure 5. Fabrication process for the thin barrier E-mode AlGaN/GaN MOSHEMT.
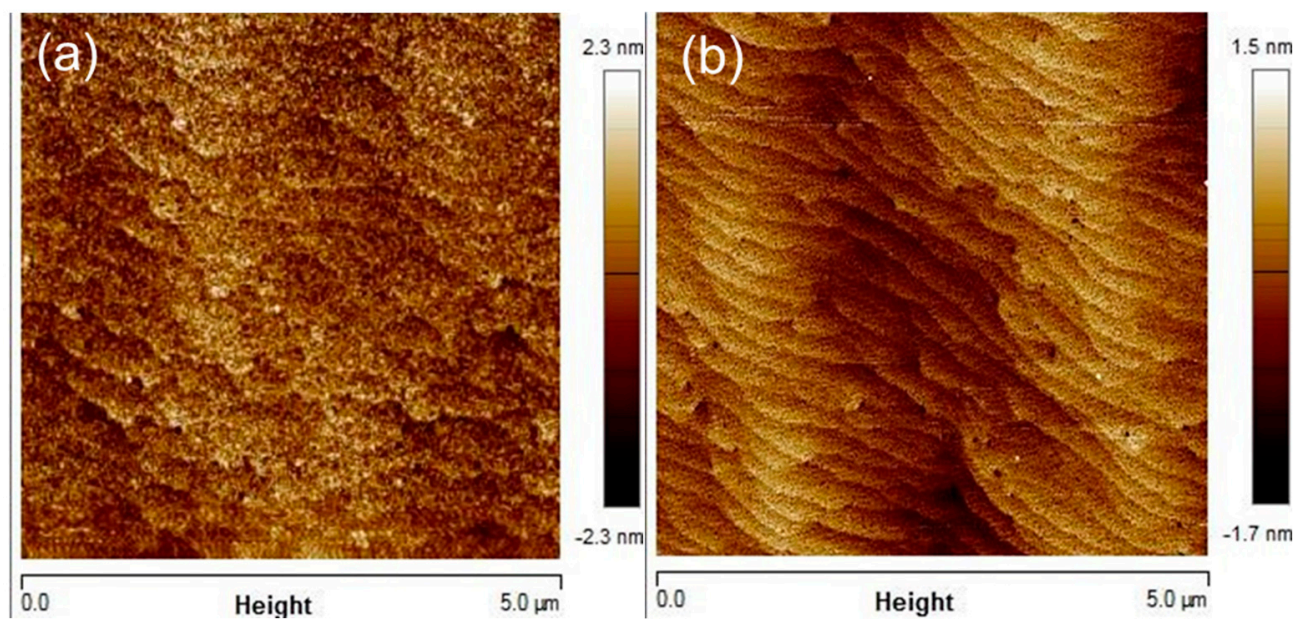

Figure 6. Surface morphology of the $\mathrm{AlGaN} / \mathrm{GaN}$ heterostructure after etching barrier layer (a) without treatment and (b) with wet surface treatment.

\section{Results and Discussion}

\subsection{X-ray Photoelectron Spectroscopy (XPS) Measurement}

X-ray photoelectron spectroscopy (XPS) was adopted to investigate the surface chemical composition after applying the wet surface treatment. Generally, an imperfect layer caused by the environment pollutants, the native oxide, and the bombardment damage existed after the gate recess process. The existence of such a layer would degrade the device characteristics. It is thus of crucial importance to address this issue especially for devices 
at millimeter-wave frequencies. Figure 7 shows the Ga $3 d$ and Al $2 p$ core-level spectra of the control sample with $\mathrm{HCl}$ surface treatment and the sample with wet surface treatment, respectively. The Ga $3 d$ and $\mathrm{Al} 2 p$ peaks were separated into four main peaks $\mathrm{Ga}-\mathrm{O}, \mathrm{Ga}-\mathrm{N}$, $\mathrm{Al}-\mathrm{O}$ and $\mathrm{Al}-\mathrm{N}$ bonds. It is obvious that the intensity of the $\mathrm{Ga}-\mathrm{O}$ and $\mathrm{Al}-\mathrm{O}$ with a larger binding energy are much lower in the experimental sample. In other words, the Ga-O and Al-O bonding proportion decreased at the surface region. Such an effect indicates that with the application of wet surface treatment, the imperfect layer can be effectively removed. In [17], the XPS analysis showed the reduction of the $\mathrm{Ga}-\mathrm{O}$ and Al-O percentage after the TMAH treatment, which was considered to be the removal of the damage and the oxides at the $\mathrm{AlGaN}$ gate surface region.
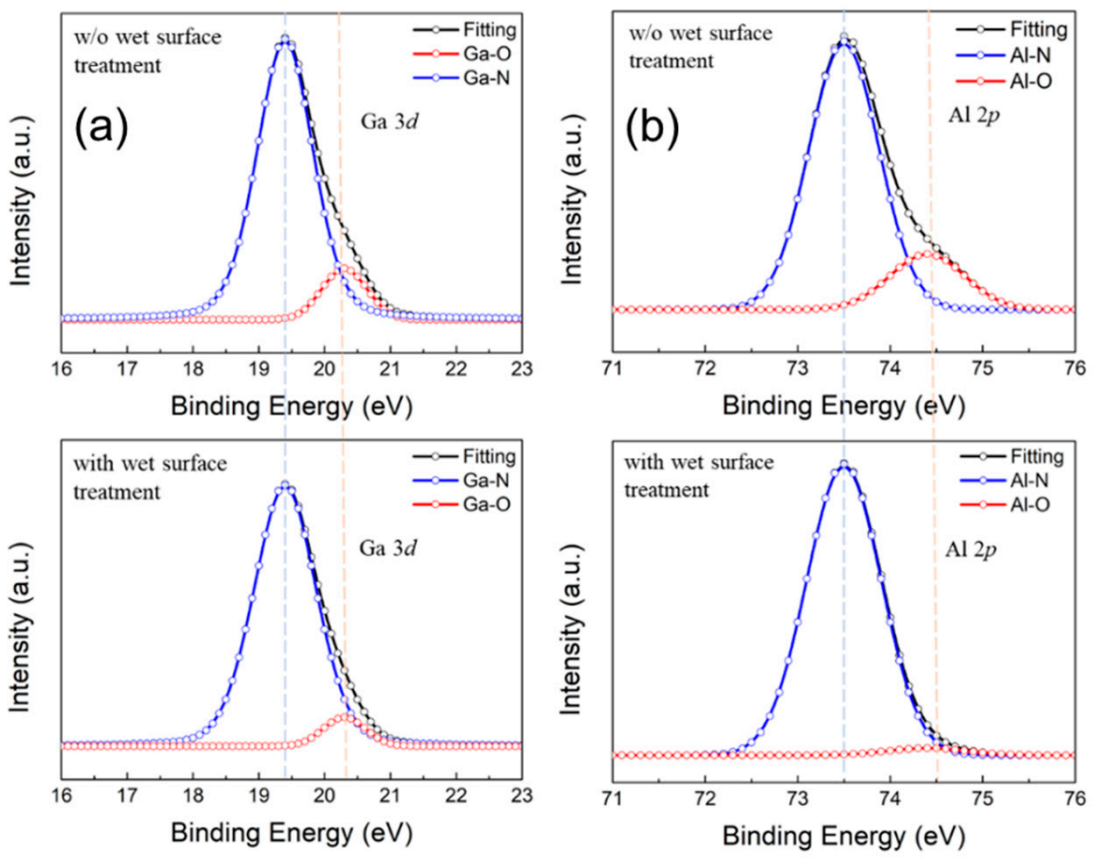

Figure 7. The X-ray photoelectron spectroscopy (XPS): (a) Ga $3 d$ and (b) Al $2 p$ core level spectra of the AlGaN surface with and without wet surface treatment.

\subsection{Direct Current (DC) and Pulsed Current-Voltage (I-V) Characteristics}

The measured DC characteristics of the thin barrier E-mode AlGaN/GaN HEMTs is shown in Figure 8. As observed, the fabricated $2 \times(0.15 \times 25) \mu \mathrm{m}^{2}$ devices with surface treatment exhibits a lower maximum drain current of $859 \mathrm{~mA} / \mathrm{mm}$ compared to the devices without surface treatment, which has a maximum current of $931 \mathrm{~mA} / \mathrm{mm}$ at $\mathrm{V}_{\mathrm{G}}=2 \mathrm{~V}$. After the wet surface treatment, a peak extrinsic transconductance $\left(\mathrm{g}_{\mathrm{m}}\right) 484 \mathrm{mS} / \mathrm{mm}$ and a threshold voltage $\left(\mathrm{V}_{\text {th }}\right)$ of $+0.13 \mathrm{~V}$ were achieved at $\mathrm{V}_{\mathrm{DS}}=5 \mathrm{~V}$ due to the removal of the surface oxidation layer by wet recess. While scaling down the distance between gate and channel, higher $\mathrm{g}_{\mathrm{m}}$ and lower current density were obtained for E-mode device. As for the gate leakage current for both cases shown in Figure 8c, further improvement in the leakage current is also observed for the device with surface treatment. The forward gate current of the device with wet surface treatment exhibited two orders of magnitude lower than that without surface treatment, evidencing the effect of the removal of the imperfect layer. Further investigation on the trapping levels at the interface was conducted through the pulsed-IV measurements. Figure 9 shows the results with a 200 ns pulse width and $0.1 \%$ duty cycle. With the gate stress measurements under a quiescent bias of $\left(\mathrm{V}_{\mathrm{GSO}}, \mathrm{V}_{\mathrm{DSO}}\right)=(-4 \mathrm{~V}, 0 \mathrm{~V})$, the device with wet surface treatment shows minor collapse ratio of $3.7 \%$ which is much smaller than that of $17.78 \%$ for the one without treatment. It is obvious that the plasma damage caused by the dry etching process can be suppressed after the combination of the oxidation and wet etching treatment. The drain lag ratio 
has also decreased from $17 \%$ to $12.58 \%$ at $\mathrm{V}_{\mathrm{GS}}=1 \mathrm{~V}$ and $\mathrm{V}_{\mathrm{DS}}=5 \mathrm{~V}$ under the condition $\left(\mathrm{V}_{\mathrm{GS}}, \mathrm{V}_{\mathrm{DS} 0}\right)=(-4 \mathrm{~V}, 10 \mathrm{~V})$. Improvement in the current collapse phenomenon has been identified from both drain and gate lad measurements. It is worth mentioning that the drain lag results are owing to the deep traps in epitaxial layers, such as GaN iron-doped buffer $[22,23]$. These trapping electrons from defects may cause the degradation of the device's electrical properties.
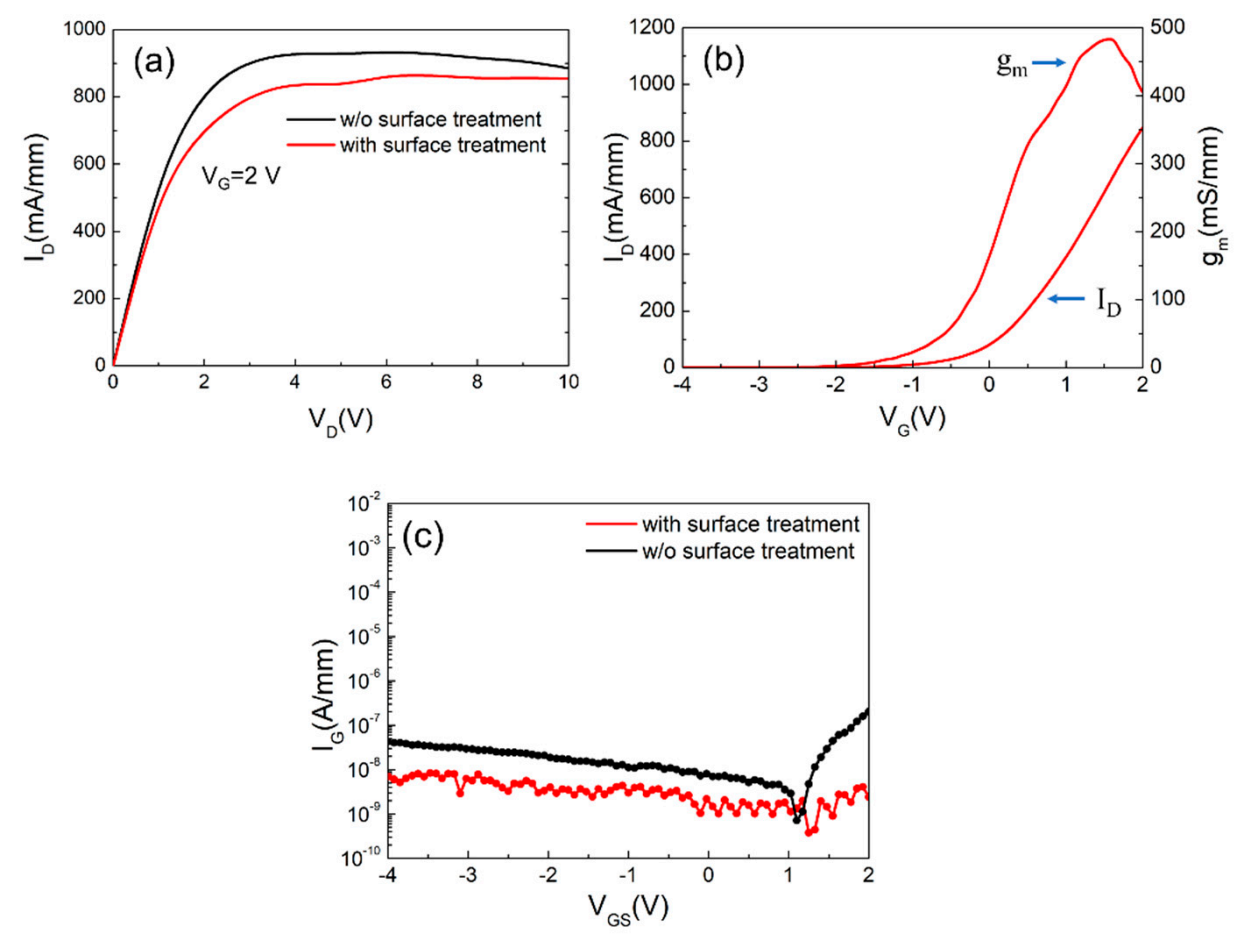

Figure 8. (a) The measured drain current as functions of drain voltage for devices with and without surface treatment. (b) The measured drain current and extrinsic transconductance $\left(g_{m}\right)$ with surface treatment. (c) Gate leakage of recess gate HEMTs with and without surface treatment.
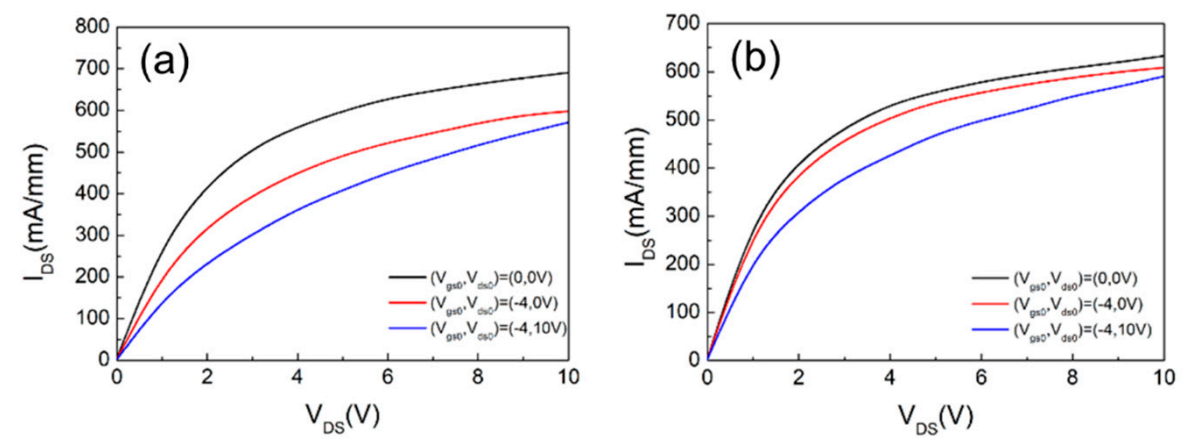

Figure 9. Pulsed I-V characterization with 200-ns pulse width and $0.1 \%$ duty cycle for $2 \times 25 \mu \mathrm{m}^{2}$ thin barrier AlGaN/GaN HEMTs (a) without and (b) with wet surface treatment.

\subsection{Small-Signal Characteristics Comparison}

The small-signal RF S-parameters were measured from $100 \mathrm{MHz}$ to $40 \mathrm{GHz}$ using a Keysight N5227B network analyzer. A standard short-open-load-through (SOLT) calibration method was adopted to calibrate the system with the reference planes set at the tips of the corresponding probes. Figure 10 shows the measurement results for the devices with and without wet surface treatment. The extracted unit current-gain cutoff frequency $\left(\mathrm{f}_{\mathrm{T}}\right)$ and the maximum oscillation frequency $\left(\mathrm{f}_{\max }\right)$ were $46 / 60 \mathrm{GHz}$ and $109 / 100 \mathrm{GHz}$ for the device with/without surface treatment. We have used the small-signal equivalent 
circuit using the procedure in [24] to extract parameters. Figure 11 shows that there is no difference between the Smith chart of the measured and fitted curves. The total gate capacitance $\left(\mathrm{C}_{\mathrm{gs}}+\mathrm{C}_{\mathrm{gd}}\right)$ for devices without and with surface treatment are $98.95 \mathrm{fF}$ and $86.7 \mathrm{fF}$, respectively. Thus, the higher cut-off frequency $\left(\mathrm{f}_{\mathrm{T}}\right)$ of the device with wet surface treatment can be attributed to the lower gate capacitance. However, slight degradation in $\mathrm{f}_{\text {max }}$ for the device with surface treatment is possibly due to the decrease of the output current and the lower 2DEG density.
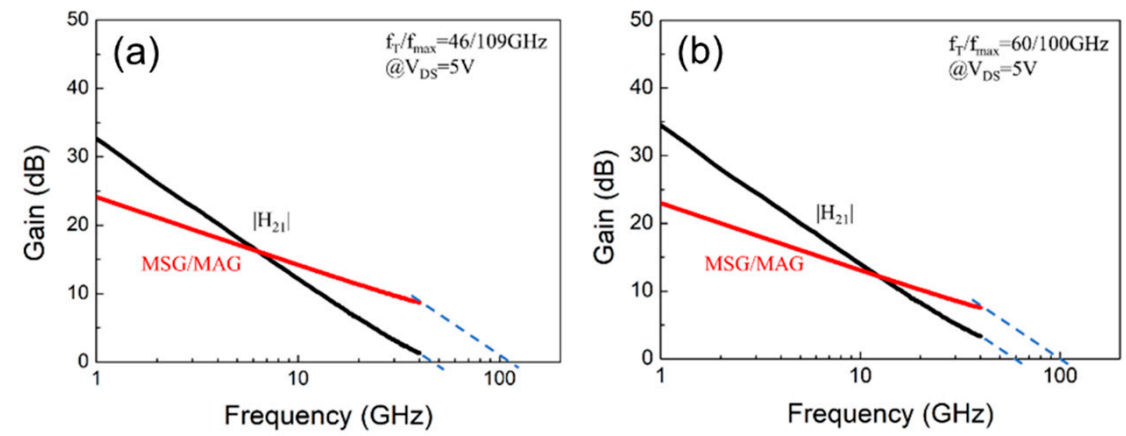

Figure 10. The extracted cut-off frequency $\left(f_{T}\right)$ and maximum oscillation frequency $\left(f_{\max }\right)$ for thin barrier AlGaN/GaN MOSHEMT devices: (a) without and (b) with surface treatment.
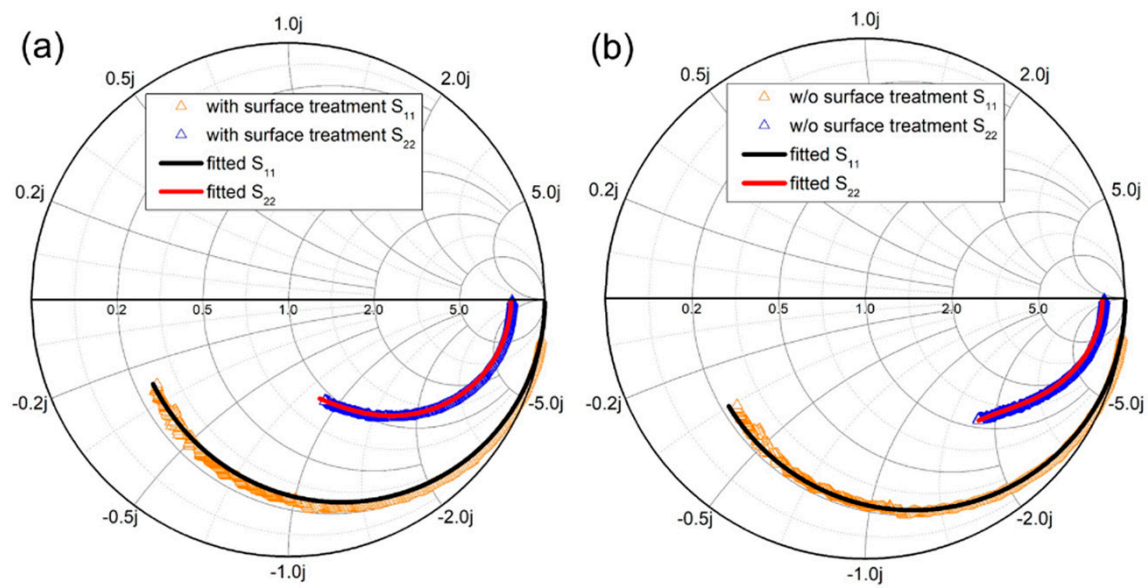

Figure 11. The Smith chart of the measured and fitted curves of the (a) with and (b) without surface treatment device.

\subsection{Large-Signal Performance}

The large-signal performance was characterized using an on-wafer load-pull system at $38 \mathrm{GHz}$ under continuous mode excitation. Figure 12 shows the measurement results with the device biased at class $A B$ operation and the impedance is optimized for maximum output power. The optimal source and load impedance for the device without treatment are $(32.20+j 24.12) \Omega$ and $(92.15+j 126.12) \Omega$ and those for the device with treatment are $(35.85+j 28.31) \Omega$ and $(226.07+j 216.15) \Omega$, respectively. Under these conditions, $a$ maximum output power density of $2.1 \mathrm{~W} / \mathrm{mm}$ with a linear power gain $\left(\mathrm{G}_{\mathrm{p}}\right)$ of $8.2 \mathrm{~dB}$ and a PAE of $22.84 \%$ were obtained at $\mathrm{V}_{\mathrm{DS}}=10 \mathrm{~V}$ for the device without wet surface treatment. On the other hand, with the suppression of current collapse, a higher maximum output power density of $3.22 \mathrm{~W} / \mathrm{mm}$ and a PAE of $34.83 \%$ were achieved for the device with surface treatment. Such a substantial improvement in the performance at Ka-band is mainly attributed to the suppression of the current collapse issue [25]. The measurement results have evidenced that the device technology presented in this paper is promising for future applications in power amplifiers at millimeter-wave frequencies. Furthermore, the proposed MOSHEMT outperforms other E-mode AlGaN/GaN HEMTs 
on SiC substrate $[4,7,26]$. The reported work exhibits a good power performance at relatively low $\mathrm{V}_{\mathrm{DS}}$. In all, the experimental results of the thin barrier E-mode AlGaN/GaN HEMT on Sapphire shows a great potential for low power consumption and low-cost power amplifier application.
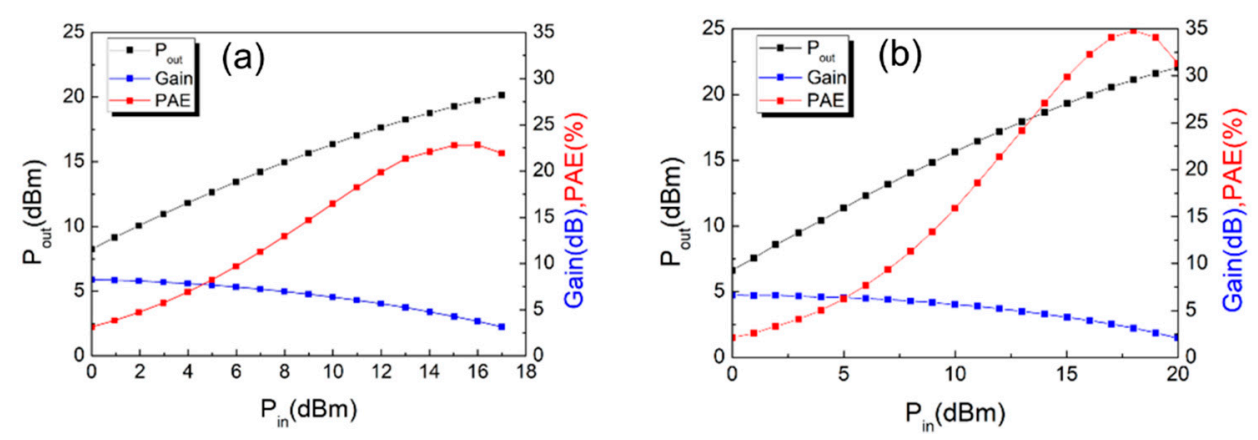

Figure 12. Large signal radiofrequency (RF) output power characteristics of (a) without (b) with wet surface treatment $\left(\mathrm{V}_{\mathrm{DS}}=10 \mathrm{~V}\right)$ at $38 \mathrm{GHz}$.

\section{Conclusions}

A high-performance thin barrier enhancement-mode AlGaN/GaN HEMT was fabricated with wet surface treatment and high-quality $\mathrm{Al}_{2} \mathrm{O}_{3}$ as the gate dielectric layer. After the dry etching process and wet etching treatment, the damaged surface layer was removed. Moreover, the current collapse was eliminated due to the reduced trapping effect. Compared to a device without surface treatment, substantial improvement in the radiofrequency (RF) performance was achieved. The device exhibited a superior power performance, including a maximum output power density of $3.22 \mathrm{~W} / \mathrm{mm}$ and a peak PAE of $34.83 \%$ at $38 \mathrm{GHz}$. These results demonstrate an attractive technique for fabricating high-performance E-mode HEMTs for power amplifier applications at millimeter-wave frequencies.

Author Contributions: Experiment, C.W. and Y.-C.C.; Analysis and writing, C.W.; Conceiving the idea, review and editing, H.-T.H., Y.-C.L., E.-Y.C. and C.-F.D.; Data curation, C.W. and Y.-C.C.; DC data analysis, C.W. and Y.-C.L.; RF measurement, H.-T.H. and Y.-F.T.; RF data analysis, C.W., H.-T.H. and Y.-F.T.; supervision, E.-Y.C. and C.-F.D. All authors have read and agreed to the published version of the manuscript.

Funding: This work was financially supported by the "Center for the Semiconductor Technology Research" from The Featured Areas Research Center Program within the framework of the Higher Education Sprout Project by the Ministry of Education (MOE) in Taiwan. Also, it is supported in part by the Ministry of Science and Technology, Taiwan, under Grant MOST 110-2634-F-009-027- as well as 110-2622-8-009-018-SB.

Institutional Review Board Statement: Not applicable.

Informed Consent Statement: Not applicable.

Data Availability Statement: The data presented in this paper are available on request from the corresponding author.

Conflicts of Interest: The authors declare no conflict of interest.

\section{References}

1. Palacios, T.; Chakraborty, A.; Rajan, S.; Poblenz, C.; Keller, S.; DenBaars, S.P.; Speck, J.S.; Mishra, U.K. High-power AlGaN/GaN HEMTs for Ka-band applications. IEEE Electron Device Lett. 2005, 26, 781-783. [CrossRef]

2. Harrouche, K.; Kabouche, R.; Okada, E.; Medjdoub, F. High Performance and Highly Robust AlN/GaN HEMTs for MillimeterWave Operation. IEEE J. Electron Devices Soc. 2019, 7, 1145-1150. [CrossRef]

3. Aubry, R.; Jacquet, J.C.; Oualli, M.; Patard, O.; Piotrowicz, S.; Chartier, E.; Michel, N.; Xuan, L.T.; Lancereau, D.; Potier, C.; et al. ICP-CVD SiN Passivation for High-Power RF InAlGaN/GaN/SiC HEMT. IEEE Electron Device Lett. 2016, 37, 629-632. [CrossRef] 
4. Feng, Z.H.; Zhou, R.; Xie, S.Y.; Yin, J.Y.; Fang, J.X.; Liu, B.; Zhou, W.; Chen, K.J.; Cai, S.J. 18-GHz 3.65-W/mm Enhancement-Mode AlGaN/GaN HFET Using Fluorine Plasma Ion Implantation. IEEE Electron Device Lett. 2010, 31, 1386-1388. [CrossRef]

5. Yu, C.J.; Hsu, C.W.; Wu, M.C.; Hsu, W.C.; Chuang, C.Y.; Liu, J.Z. Improved DC and RF Performance of Novel MIS p-GaN-Gated HEMTs by Gate-All-Around Structure. IEEE Electron Device Lett. 2020, 41, 673-676. [CrossRef]

6. Moon, J.; Wu, S.; Wong, D.; Milosavljevic, I.; Conway, A.; Hashimoto, P.; Hu, M.; Antcliffe, M.; Micovic, M. Gate-Recessed AlGaN-GaN HEMTs for High-Performance Millimeter-Wave Applications. IEEE Electron Device Lett. 2005, 26, 348-350. [CrossRef]

7. Maroldt, S.; Haupt, C.; Pletschen, W.; Müller, S.; Quay, R.; Ambacher, O.; Schippel, C.; Schwierz, F. Gate-Recessed AlGaN/GaN Based Enhancement-Mode High Electron Mobility Transistors for High Frequency Operation. Jpn. J. Appl. Phys. 2009, 48,04 C083. [CrossRef]

8. Schuette, M.L.; Ketterson, A.; Song, B.; Beam, E.; Chou, T.M.; Pilla, M.; Tserng, H.Q.; Gao, X.; Guo, S.; Fay, P.J.; et al. Gate-Recessed Integrated E/D GaN HEMT Technology With $\mathrm{f}_{\mathrm{T}} / \mathrm{f}_{\max }>300 \mathrm{GHz}$. IEEE Electron Device Lett. 2013, 34, 741-743. [CrossRef]

9. Makiyama, K.; Ozaki, S.; Ohki, T.; Okamoto, N.; Minoura, Y.; Niida, Y.; Kamada, Y.; Joshin, K.; Watanabe, K.; Miyamoto, Y. Collapse-free high power InAlGaN/GaN-HEMT with $3 \mathrm{~W} / \mathrm{mm}$ at $96 \mathrm{GHz}$. In Proceedings of the International Electron Devices Meeting (IEDM), Washington, DC, USA, 7-9 December 2015; pp. 9.1.1-9.1.4.

10. Kim, D.; Kumar, V.; Lee, J.; Yan, M.; Dabiran, A.M.; Wowchak, A.M.; Chow, P.P.; Adesida, I. Recessed 70-nm gate-length $\mathrm{AlGaN} / \mathrm{GaN}$ HEMTs fabricated using an $\mathrm{Al}_{2} \mathrm{O}_{3} / \mathrm{SiNx}$ dielectric layer. IEEE Electron Device Lett. 2009, 30, $913-915$.

11. Huang, S.; Liu, X.; Zhang, J.; Wei, K.; Liu, G.; Wang, X.; Zheng, Y.; Liu, H.; Jin, Z.; Zhao, C.; et al. High RF performance enhancement-mode $\mathrm{Al}_{2} \mathrm{O}_{3} / \mathrm{AlGaN} / \mathrm{GaN}$ MIS-HEMTs fabricated with high-temperature gate-recess technique. IEEE Electron Device Lett. 2015, 36, 754-756. [CrossRef]

12. Lin, Y.-K.; Noda, S.; Huang, C.-C.; Lo, H.-C.; Wu, C.-H.; Luc, Q.H.; Chang, P.-C.; Hsu, H.-T.; Samukawa, S.; Chang, E.Y. Highperformance $\mathrm{GaN}$ MOSHEMTs fabricated with $\mathrm{ALD} \mathrm{Al}_{2} \mathrm{O}_{3}$ Dielectric and NBE gate recess technology for high frequency power applications. IEEE Electron Device Lett. 2017, 38, 771-774. [CrossRef]

13. Zhang, Y.; Huang, S.; Wei, K.; Zhang, S.; Wang, X.; Zheng, Y.; Liu, G.; Chen, X.; Li, Y.; Liu, X. Millimeter-wave AlGaN/GaN HEMTs with $43.6 \%$ power-added-efficiency at $40 \mathrm{GHz}$ fabricated by atomic layer etching gate recess. IEEE Electron Device Lett. 2010, 41, 701-704. [CrossRef]

14. Mi, M.; Ma, X.-H.; Yang, L.; Lu, Y.; Hou, B.; Zhu, J.; Zhang, M.; Zhang, H.-S.; Zhu, Q.; Yang, L.-A.; et al. Millimeter-wave power $\mathrm{AlGaN} / \mathrm{GaN}$ HEMT using surface plasma treatment of access region. IEEE Trans. Electron Devices 2017, 64, 4875-4881. [CrossRef]

15. Mi, M.-H.; Ma, X.-H.; Yang, L.; Hou, B.-; Zhu, J.-J.; He, Y.-L.; Zhang, M.; Wu, S.; Hao, Y. 90 nm gate length enhancement-mode AlGaN/GaN HEMTs with plasma oxidation technology for high-frequency application. Appl. Phys. Lett. 2017, 111, 173502. [CrossRef]

16. Tingting, Y.; Xinyu, L.; Yingkui, Z.; Chengzhan, L.; Ke, W.; Guoguo, L. Impact of UV/ozone surface treatment on AlGaN/GaN HEMTs. J. Semicond. 2009, 30, 124001. [CrossRef]

17. Do, J.-W.; Jung, H.-W.; Shin, M.J.; Ahn, H.-K.; Kim, H.; Kim, R.-H.; Cho, K.J.; Chang, S.-J.; Min, B.-G.; Yoon, H.S.; et al. The effects of tetramethylammonium hydroxide treatment on the performance of recessed-gate AlGaN/GaN high electron mobility transistors. Thin Solid Films 2017, 628, 31-35. [CrossRef]

18. Lee, N.-H.; Lee, M.; Choi, W.; Kim, D.; Jeon, N.; Choi, S.; Seo, K.-S. Effects of various surface treatments on gate leakage, subthreshold slope, and current collapse in AlGaN/GaN high-electron-mobility transistors. Jpn. J. Appl. Phys. 2014, 53, 04EF10. [CrossRef]

19. Bardwell, J.; Haffouz, S.; McKinnon, R.; Storey, C.; Tang, H.; Sproule, G.I.; Roth, D.; Wang, R. The effect of surface cleaning on current collapse in AlGaN/GaN HEMTs. Electrochem. Solid-State Lett. 2007, 10, H46-H49. [CrossRef]

20. Wang, L.; Bu, Y.; Ao, J.-P. Effect of oxygen plasma treatment on the performance of AlGaN/GaN ion-sensitive field-effect transistors. Diam. Relat. Mater. 2017, 73, 1-6. [CrossRef]

21. Liu, S.C.; Chen, B.Y.; Lin, Y.C.; Hsieh, T.E.; Wang, H.C.; Chang, E.Y. GaN MIS-HEMTs with nitrogen passivation for power device application. IEEE Electron Device Lett. 2014, 35, 1001-1003.

22. Desmaris, V.; Rudzinski, M.; Rorsman, N.; Hageman, P.; Larsen, P.; Zirath, H.; Rodle, T.; Jos, H. Comparison of the DC and microwave performance of AlGaN/GaN HEMTs grown on SiC by MOCVD with Fe-doped or unintentionally doped GaN buffer layers. IEEE Trans. Electron Devices 2006, 53, 2413-2417. [CrossRef]

23. Meneghini, M.; Rossetto, I.; Bisi, D.; Stocco, A.; Chini, A.; Pantellini, A.; Lanzieri, C.; Nanni, A.; Meneghesso, G.; Zanoni, E. Buffer traps in Fe-doped AlGaN/GaN HEMTs: Investigation of the physical properties based on pulsed and transient measurements IEEE Trans. Electron Devices 2014, 61, 4070-4077. [CrossRef]

24. Jarndal, A.; Kompa, G. A New Small-Signal Modeling Approach Applied to GaN Devices. IEEE Trans Microwave Theory Tech. 2005, 53, 3440-3448. [CrossRef]

25. Lin, S.; Wang, M.; Xie, B.; Wen, C.P.; Yu, M.; Wang, J.; Hao, Y.; Wu, W.; Huang, S.; Chen, K.J.; et al. Reduction of current collapse in GaN high-electron mobility transistors using a repeated ozone oxidation and wet surface treatment. IEEE Electron Device Lett. 2015, 36, 757-759.

26. Ohki, T.; Kikkawa, T.; Kanamura, M.; Imanishi, K.; Makiyama, K.; Okamoto, N.; Joshin, K.; Hara, N. An over 100 W AlGaN/GaN enhancement-mode HEMT power amplifier with piezoelectric-induced cap structure. Phys. Stat. Solidi (C) 2009, 6, 1365-1368. [CrossRef] 